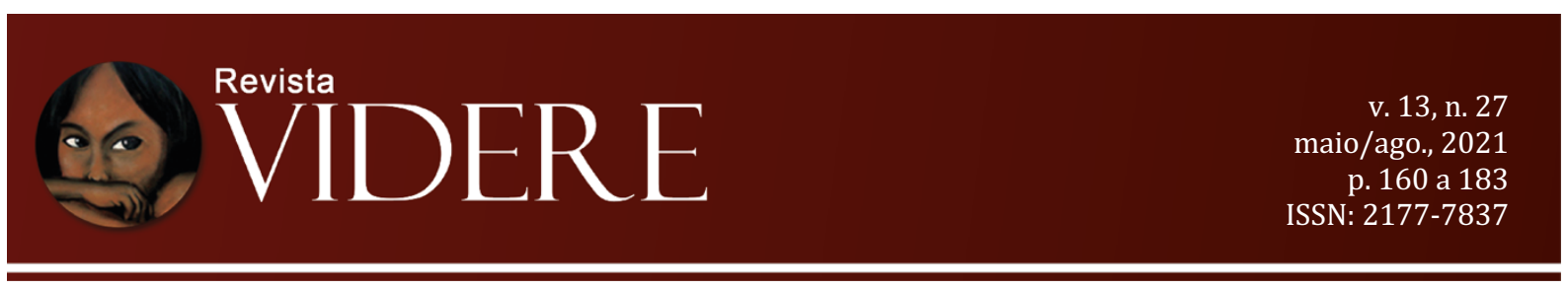

\title{
PROPRIEDADE E POVOS ORIGINÁRIOS: LIMITES E POSSIBILIDADES DA POSSE COLETIVA COMO GARANTIA DE MAIOR EFETIVIDADE DA CONSTITUIÇÃO FEDERAL DE 1988
}

\author{
PROPERTY AND ORIGINAL PEOPLE: LIMITS AND MEANS OF THE COLLECTIVE \\ POSSESSION AS GUARANTEE OF BIGGER EFFECTIVENESS OF THE FEDERAL \\ CONSTITUTION OF 1988
}

\begin{abstract}
PROPRIEDAD Y PUEBLOS ORIGINARIOS: LIMITES Y POSIBILIDADES DE LA POSESIÓN COLECTIVA COMO GARANTÍA DE MAYOR EFECTIVIDAD DE LA CONSTITUCIÓN FEDERAL DE 1988
\end{abstract}

\author{
Marco Antônio Rodrigues \\ Mestre em Direito \\ Universidade Federal de Mato Grosso do Sul \\ marcorod.adv@gmail.com \\ https://orcid.org/0000-0003-0858-2183 \\ Andréa Lúcia Cavararo Rodrigues \\ Mestra em Antropologia Social \\ Universidade Federal de Mato Grosso do Sul \\ andreacavararo@gmail.com \\ https://orcid.org/0000-0002-4149-8066 \\ Antonio Hilário Aguilera Urquiza \\ Doutor em Antropologia \\ Universidade Federal de Mato Grosso do Sul \\ hilarioaguilera@gmail.com \\ https://orcid.org/0000-0002-3375-8630
}

Resumo: O presente artigo é fruto do projeto de pesquisa em andamento, intitulado OGUATA GUASU E TERRITÓRIO: Uma análise antropológica da mobilidade Guarani nas fronteiras de Mato Grosso do Sul, financiado pelo CNPq. O presente artigo tem por objetivo analisar as diferenças e significações da propriedade em uma perspectiva jurídico-antropológica. A hipótese de pesquisa baseia-se na seguinte indagação: é possível instituir a propriedade ou a posse coletiva em prol dos povos originários? Por meio da análise do problema a partir dos diversos fatores que o compõem, chegou-se ao resultado parcial, demonstrando-se que o naturalismo jurídico influenciou a formação de leis em que os indígenas passaram a ser usufrutuários dos territórios ocupados, cujas consequências se dão por meio da ineficácia de 
disposições constitucionais. Através do método indutivo e da utilização de fontes bibliográficas, documentais, doutrinárias e jurisprudenciais, este trabalho buscará atingir o seu objetivo.

Palavras-chave: Povos originários. jusnaturalismo. propriedade. Constituição Federal de 1988.

\begin{abstract}
This article is the result of an ongoing research project, entitled OGUATA GUASU E TERRITÓRIO: An anthropological analysis of Guarani mobility on the borders of Mato Grosso do Sul, funded by CNPq. This article aims to analyze the differences and meanings of property in a legal-anthropological perspective. The research hypothesis is based on the following question: is it possible to institute collective ownership or possession for the benefit of the original peoples? By analyzing the problem from the various factors that compose it, the partial result was arrived at, demonstrating that legal naturalism influenced the formation of laws in which the indigenous people became usufructuaries in the occupied territories, the consequences of which are given through the ineffectiveness of constitutional provisions. Through the inductive method and the use of bibliographic, documentary, doctrinal and jurisprudential sources, this work will seek to achieve its objective.
\end{abstract}

Keywords: Originating peoples. jusnaturalism. property. Federal Constitution of 1988.

Resumen: el presente artículo es el resultado del proyecto de investigación en curso, con título: OGUATA GUASU Y TERRITÓRIO: UN análisis antropológico de la movilidad guaraní en las fronteras de Mato Grosso do Sul, financiado por el CNPq. Este artículo tiene como objetivo analizar las diferencias y significaciones de la propiedad en una perspectiva jurídicoantropológica. La hipótesis de investigación se basa en la siguiente pregunta: ¿es posible instituir la propiedad o la posesión colectiva en beneficio de los pueblos originarios? Al analizar el problema a partir de los diversos factores que lo componen, se llegó al resultado parcial, demostrando que el naturalismo jurídico influenció la formación de leyes en que los indígenas se convirtieron en usufructuarios de los territorios ocupados, cuyas consecuencias ocurren por medio de la ineficacia de disposiciones constitucionales. A través del método inductivo y de la utilización de fuentes bibliográficas, documentales, doctrinarias e jurisprudenciales, este trabajo buscará lograr su objetivo.

Palabras-clave: Pueblos originarios. iusnaturalismo. propiedad. Constitución Federal de 1988.

\title{
1 Introdução
}

O presente artigo tem por objetivo analisar a questão indígena sob o viés jurídicoantropológico, buscando responder à seguinte indagação: é possível estabelecer a propriedade ou posse coletiva dos territórios tradicionalmente ocupados pelos povos originários?

Ao longo dos anos, tem se discutido os problemas relativos à posse da terra e dos territórios pertencentes aos indígenas, levando a diversas opiniões e contradições sobre esse tema, porém as soluções ainda se encontram indeterminadas. 
A quem se pode atribuir tais distorções diante da aparente ineficácia de leis e disposições constitucionais que traduzem na desolação e desesperança dos povos originários em face do panorama de insegurança jurídica gerado pela política estatal, constantemente sujeita a mudanças?

Há um ambiente de desequilíbrio e insegurança, não só jurídica, mas também social, decorrente da ineficácia de leis e da própria Constituição Federal quando se trata de povos originários, dependendo do contexto em que estejam colocados.

Diante dessas premissas, cabe destacar que o artigo 231 da Constituição Federal de 1988 pode ter sua aplicabilidade na formação de leis e demais normas voltadas aos indígenas, porém sua efetividade está sujeita a certos limites, sutilmente omitidos, e que resultam em sua ineficácia quando a discussão envolve a temática acerca de território e propriedade.

Por sua natureza, a política está sujeita a alterações, bem como o próprio Estado, a sociedade e seus valores morais e éticos, porém a propriedade possui o seu sentido, sua importância e essência quase imutáveis, atravessando milênios sem perder nenhum destes atributos.

Em decorrência dessas características, verifica-se que a propriedade é protegida por um manto de leis que lhe conferem segurança, constatando-se uma gama de disposições legais que amparam aqueles que possuem títulos, que se pode constatar na Constituição Federal e no Código Civil ${ }^{1}$.

Nessa ótica, na relação direta com a propriedade temos a figura do usufrutuário ${ }^{2}$. Por definição, usufrutuário é aquele que possui direito real sobre coisa alheia. Em outras palavras, é um direito conferido a alguém, durante certo tempo, para gozar ou fruir de um bem cuja propriedade pertence a outrem.

O artigo 231 da Constituição Federal prevê que são reconhecidos aos índios sua organização social, costumes, línguas, crenças e tradições, e os direitos originários sobre as terras que tradicionalmente ocupam, competindo à União demarcá-las, proteger e fazer respeitar todos os seus bens (BRASIL, 1988).

\footnotetext{
${ }^{1} \mathrm{O}$ direito de propriedade é um direito real complexo, constante no art. 1.228 do Código Civil, mediante faculdades reais de usar, gozar/fruir, dispor e reivindicar da coisa, conforme a sua função social. A Constituição Federal aborda o direito de propriedade em seu artigo $5^{\circ}$, inciso XXII, de forma que representa um direito e uma garantia fundamental. Já no art. $5^{\circ}$, inciso XXIII, a Constituição de 1988 dispõe que a propriedade visa a atender a sua função social (nota do autor).

${ }^{2} \mathrm{O}$ usufruto representa o exercício simultâneo de dois atributos da propriedade, os direitos de usar e fruir. Conceitua-se como o direito real de uso e fruição sobre coisa alheia que atribui ao titular, denominado de usufrutuário, temporariamente, o direito de usar e fruir do bem móvel, imóvel ou universalidades pertencentes ao proprietário (nota do autor).
} 
Interpretando-se essa disposição constitucional, verifica-se que as terras indígenas são pertencentes à União Federal, e os ocupantes desses territórios são meros usufrutuários, estando sujeitos às intempéries e vontades do poder estatal, impedidos de contar com um aparelhamento jurídico que garanta maior eficácia e aplicabilidade das normas constitucionais em seu favor, relegando-os a um estado de vulnerabilidade crescente.

Se a estrutura do Estado confere validade e eficácia somente a leis positivadas ${ }^{3}$ eis um primeiro óbice para que não se reconheçam os direitos dos indígenas, fundamentados no costume e em regras consagradas no direito consuetudinário.

A valoração dos costumes, crenças e tradições dos indígenas está prevista em apenas um capítulo da Constituição Federal, e a questão da territorialidade, muito cara aos indígenas, e principal ponto deste trabalho, leva à análise do porquê de os direitos originários dos indígenas sobre as terras tradicionalmente ocupadas não têm sido observados.

Diante dessas questões, o artigo buscará analisar alguns fatores que levaram à vulnerabilidade dos povos originários exatamente no quesito da territorialidade, considerandose, historicamente, o jusnaturalismo como influenciador da elaboração de normas pelo ente estatal no tocante à propriedade, buscando pontos que evidenciem os motivos pelos quais os povos indígenas ficaram na condição de usufrutuários das terras ocupadas.

O tema pesquisado é interdisciplinar, e os fenômenos e acontecimentos não são simples, mas compostos por diversas informações, que se articulam e se distanciam em alguns momentos, sendo essa complexidade o grande motor da pesquisa.

Inicialmente, o artigo irá abordar a população estudada e algumas considerações antropológicas, a justificativa do tema e a metodologia empregada.

Após, o artigo irá analisar o jusnaturalismo, suas características e influência sobre a norma, além de trazer algumas definições acerca das normas não escritas e fontes do direito, analisando alguns critérios para o seu reconhecimento.

Ao final, o artigo trará algumas reflexões acerca da validade e eficácia do direito consuetudinário diante do ordenamento jurídico e, por último, irá delinear algumas possibilidades em termos da posse coletiva e os efeitos imediatos da condição de usufrutuários pelos indígenas, mostrando que o usufruto é inaplicável por limitar a esfera de direitos das populações indígenas e a sua ineficácia contribuir para agravamento do problema do reconhecimento das terras originariamente ocupadas.

\footnotetext{
${ }^{3}$ Leis escritas e decorrentes de um processo legislativo (nota do autor).
} 
Historicamente, coube ao Estado elaborar normas e estabelecer leis e o direito a fim de regular a vida em sociedade. Dessa forma, os Direitos Humanos, transculturais, também estão vinculados ao Estado, acarretando problemas quanto à sua efetivação devido a estar conciliado com a política.

O poder constituinte originário consagrou um capítulo aos indígenas na Constituição Federal, porém muitas questões subjacentes ficaram de fora do texto constitucional, gerando incertezas e insegurança, que repercutem na realidade desses povos.

\section{A Importância do Território para os Povos Originários ${ }^{4}$}

Segundo Aguilera Urquiza (2013, p. 07), as cidades fronteiriças do Mato Grosso do Sul tornam-se verdadeiros laboratórios de estudo do processo de inserção dos migrantes, sendo um espaço privilegiado para a discussão dos temas acerca da diversidade e da trajetória histórica e cultural de povos originários.

No tocante ao aspecto metodológico, o problema teórico da teoria da complexidade é o da possibilidade de entrar nas caixas-pretas e, considerando-se a complexidade organizacional e lógica, a dificuldade não está somente na renovação da concepção do objeto, mas na reversão das perspectivas epistemológicas do sujeito ou observador científico, que passa a aceitar a imprecisão, a ambiguidade e a contradição como componentes do fenômeno pesquisado.

Morin (2011, p. 08) informa que os fenômenos antropossociais não podem responder a princípios de inteligibilidade aplicáveis aos fenômenos naturais, sendo necessário enfrentar sua complexidade de acordo com suas características e como o problema se apresenta.

Pode-se dizer que o que é complexo diz respeito, por um lado, ao mundo empírico, à incerteza, à incapacidade de ter certeza de tudo, de formular uma lei, de conceber uma ordem absoluta. Por outro lado, diz respeito a alguma coisa de lógico, isto é, à capacidade de evitar contradições devido a uma visão multidimensional do pesquisador (MORIN, 2011, p. 68).

Uma das principais motivações para os conflitos com os indígenas é a posição dominante do Estado, e a fricção ocasionada pelas diferentes percepções acerca do que é território, fronteira e mobilidade humana, que são valores intrínsecos à cultura dos povos originários.

\footnotetext{
${ }^{4}$ Este capítulo busca explicar a importância da metodologia empregada diante do problema proposto e dos vários fatores que envolvem o tema pesquisado, pois além da abordagem dos aspectos antropológicos, tem-se aspectos históricos e jurídicos envolvidos (nota do autor).
} 
Considerando a historicidade, é possível ter-se uma visão ampla acerca das dificuldades enfrentadas pelos povos indígenas Guarani e Kaiowá fronteiriços do Estado do Mato Grosso do Sul, devido aos acontecimentos ocorridos desde o seu confinamento em pequenas reservas ${ }^{5}$.

Os Guarani e Kaiowá fronteiriços do Estado do Mato Grosso do Sul representam a população indígena mais numerosa e, segundo a $\mathrm{FUNAI}^{6}$, contando com aproximadamente 51 mil indivíduos em 2019, sendo a etnia que mais sofreu os impactos das políticas expansionistas empreendidas pelo Estado brasileiro na região.

A pesquisa justifica-se por sua relevância social, abrangendo os povos originários Guarani e Kaiowá da região de fronteira do Estado do Mato Grosso do Sul, podendo ser ampliada a outras etnias e regiões brasileiras, haja vista a generalidade do problema.

O que se verificou na América Latina foi a formação de Estados Nacionais com a sobreposição de uma estrutura jurídica e de dominação estatal sobre diversos territórios tradicionalmente habitados por populações milenares, e que foram desalojadas de seus locais, de sua cultura e, por conseguinte, tiveram suas leis e costumes relegados a segundo plano e não recepcionados pela estrutura jurídico-normativa que a partir de então se estabeleceu.

A partir do período em que os países adquiriram sua autonomia em decorrência da criação dos Estados Nacionais da América do Sul, as fronteiras regionais foram demarcadas pelo critério de fronteiras naturais ${ }^{7}$, ignorando, por conseguinte, as fronteiras do território tradicional dos Guarani e Kaiowá, que terminaram sendo cindidas ao meio, como se pode constatar no território tradicional Ñande Ru Marangatu, localizado na fronteira Brasil/Paraguai, no município de Antônio João/ $\mathrm{MS}^{8}$, conforme se verifica a seguir (CAVARARO RODRIGUES, 2019, p. 36).

\footnotetext{
${ }^{5}$ Segundo Pereira (2012), entre 1915 e 1928, o Serviço de Proteção aos Índios (SPI) requereu áreas de terra junto ao antigo Estado de Mato Grosso e demarcou oito pequenas reservas destinadas ao recolhimento da população de centenas de grupos Guarani e Kaiowá que viviam no Estado. O órgão indigenista oficial do Estado brasileiro considerava necessária a criação destes espaços por considerar importante a proteção aos povos indígenas diante ao avanço desenfreado das frentes pioneiras de ocupação da terra, que vinha ocasionando a dizimação de inúmeras etnias indígenas, porém o processo de demarcação de reservas Guarani e Kaiowá constituiu-se na assimilação forçada dessa população à cultura e sociedade nacional, não lhes oportunizando qualquer outra alternativa. A escolha desses espaços foi baseada em áreas próximas a povoamentos de não indígenas, como exemplo o caso das reservas de Dourados, Caarapó, Amambai, Limão Verde, Sassoró, Taquaperi, Porto Lindo e Pirajuí (nota do autor). ${ }^{6}$ Fundação Nacional do Índio (nota do autor).

${ }^{7}$ Dentre as teorias adotadas, cumpre destacar a Teoria da Fronteira de Civilização, em que as fronteiras são determinadas por aspectos econômicos, religiosos e pelas instituições jurídicas que regem as populações. Considerando que a Teoria das Fronteiras Naturais foi determinante para o estabelecimento da fronteira entre Brasil e Paraguai, Gabaglia (2014, p. 14) informa que existem duas maneiras de o Estado acrescer o seu território: uma originária, decorrente de ocupação, e outra derivada, em decorrência de tratados ou posse imemorial. (nota do autor)

${ }^{8}$ Eremites de Oliveira e Pereira (2009) constataram que os trabalhos da Comissão de Limites para demarcação das fronteiras entre o Brasil e o Paraguai ocorreram no período de 1872 até 1874, sendo realizados sem observar os
} 


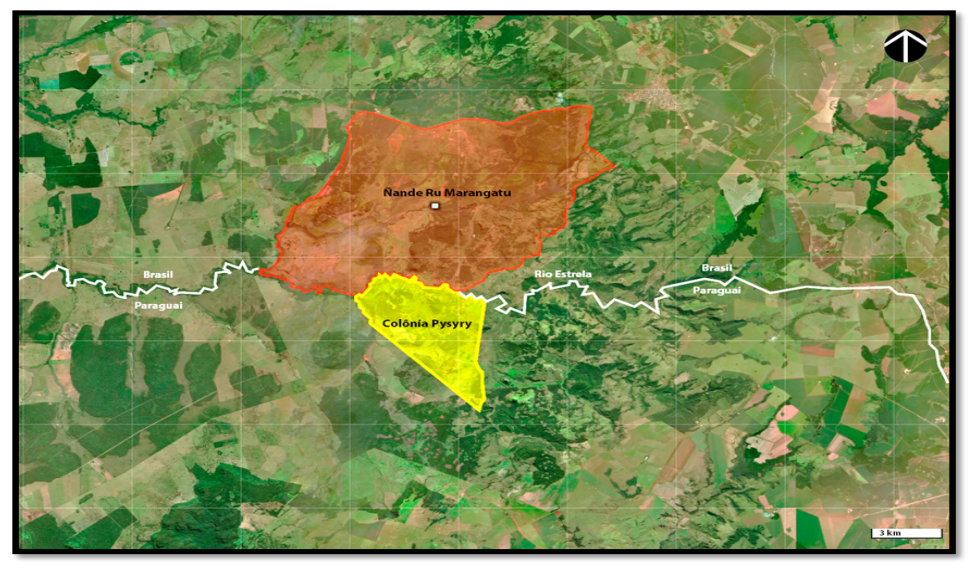

Figura 01 - Território Indígena Nande Ru Marangatu (Brasil) e Colônia Pysyry (Paraguai). Fonte: Cavararo Rodrigues, 2019, p. 36.

O Estado, a partir de sua gênese, agregou aos territórios valor monetário, pouco importando a sua destinação e se irá sofrer degradação, ao passo que os indígenas valorizam e atribuem ao mesmo território um valor transcendental, além de primar pela sua preservação em prol de gerações futuras, diferenças essas cuja lente estatal é incapaz de perceber.

Os conceitos de posse e propriedade para os indígenas não significam a simples ocupação da terra como entendido pelo Estado. A terra indígena possui conotação política, abrigando várias comunidades e possui fronteiras fixas também demarcadas, mas por critérios diferentes dos utilizados pela lei positivada.

Trata-se de um território que é englobante e cujos ocupantes pertencem a uma identidade étnica juridicamente reconhecida e comum, definida como parentela. Pressupõe-se que os ocupantes deste território englobante se percebam enquanto parte de uma coletividade, partilhando interesses comuns, devendo buscar a sustentabilidade ambiental de suas terras e a sustentabilidade social e cultural do seu modo de vida (ALENCAR, 2004, p. 69).

Silva (1992, p. 46) nos adverte que a posse indígena extrapola da órbita puramente privada porque não é, e nunca foi, uma simples ocupação da terra para explorá-la, mas base de seu habitat, no sentido ecológico de interação do conjunto de elementos naturais e culturais que

territórios indígenas existentes entre elas, como foi o caso da região que compreende a extensão do território tradicional de $\tilde{N}$ ande Ru Mangaratu localizado em Antônio João/MS até a colônia Pysyry, localizada em território do país vizinho, Paraguai (nota do autor). 
propiciam o desenvolvimento equilibrado da vida humana, e esse tipo de relação não conseguirá encontrar agasalho nas limitações individualistas do direito privado.

Na questão do domínio, as populações indígenas passaram a ter outra dimensão desse conceito ao se depararem com a sociedade nacional, haja vista a assimetria de poder entre os grupos étnicos minoritários e os grandes empreendimentos públicos e privados nacionais, que terminam por subverter toda uma relação de posse herdada imemorialmente.

Dentro do processo de construção dos Estados Nacionais, em regra, houve a privação da liberdade dos povos indígenas em praticar seus deslocamentos espaciais dentro da extensão dos seus territórios ${ }^{9}$, valendo recordar Colman (2015, p. 21), quando afirma que migrar está intrinsecamente ligado ao movimento espacial de uma população e, conforme essa autora, os deslocamentos espaciais ocorrem em virtude de catástrofes naturais, guerras, perseguições e outros fatores decorrentes da ação humana.

Dessa forma, o povo Guarani, que vivia há centenas de anos em toda a região (bacia do Rio da Prata e do Rio Paraguai, nas fronteiras entre Brasil, Paraguai e Argentina), simplesmente foi desconsiderado em suas especificidades e direitos de autonomia sobre seu território e, aos poucos, foram sendo "empurrados" e separados pelo processo de colonização, além de serem destituídos da quase totalidade dos seus territórios tradicionais ${ }^{10}$.

Em face do aspecto multicultural de nosso país, é inconcebível que haja a prevalência de uma cultura sobre outra, levando a situações de submissão, negação e exclusão de umas em relação à outras. Cabe destacar que o sistema político brasileiro, cuja organização jurídica seguiu os passos, foi baseado em um sistema de exclusão social que terminou por não considerar a diversidade de questões culturais existentes ${ }^{11}$.

\footnotetext{
${ }^{9}$ Povos indígenas e ente estatal estão em lados opostos, e esse fato é constatado a partir da publicação da Mensagem de Veto $n^{\circ}$ 163/2017 (BRASIL, 2017), pois ela rechaça aspectos como mobilidade, fronteira e territorialidade em favor dos indígenas, restringindo direitos subjetivos e dificultando a aplicação das normas constitucionais em sua plenitude (nota do autor).

${ }^{10}$ De acordo com Brand (1993, p. 126), os indígenas perderam rapidamente seus territórios tradicionais devido à exploração econômica moderna, sofrendo agressão em seu modo de ser devido às alterações no meio ambiente em consequência do desmatamento acelerado (nota do autor).

${ }^{11}$ Segundo Manuela Carneiro da Cunha (CUNHA, 2017, p. 261) a participação, ou interferência, historicamente marcante do Estado sobre as sociedades indígenas dá-se por meio da tutela ou custódia em face das terras indígenas, e a aparente proteção histórica do Estado não se deve à ignorância desses povos acerca dos usos e costumes da sociedade, mas em decorrência de uma grande dívida histórica (nota do autor).
} 


\section{Jusnaturalismo, Norma e Fontes do Direito}

O jusnaturalismo foi a base ideológica para a teoria constitucional e política, além de ter traçado os princípios fundamentais do direito. Tais princípios foram recepcionados pelo Estado de direito burguês, que aglutinou esses conceitos em torno de uma ordem jurídica que buscava abranger não só a justiça, mas os interesses extrajurídicos, levando o direito a abordar questões que passaram a agregar a ordem jurídica ao fato social, vindo a sedimentar uma concepção jusnaturalista (WIEACKER, 1967, p. 25).

Nessa ótica, o direito estatal e o direito natural não se encontram numa relação de antítese, mas de integração. O que muda na passagem não é a substância, mas a forma; não é, portanto, o conteúdo da regra, mas o modo de fazê-la valer.

A essência do direito natural está baseada no direito comum a todos os homens, tal qual fosse dado pela divindade e relativo à própria natureza de todas as coisas e do próprio ser humano.

Heck (2008, p. 215) informa que o jusnaturalismo perfaz uma doutrina jurídica que prescreve um conjunto de leis para a conduta humana, denominado direito natural, cuja validade intersubjetiva não coincide com a validade reivindicada pelo conjunto normativo do juspositivismo do Estado de direito. O princípio filosófico da lei natural é eticamente superior aos sistemas de direito positivo dos Estados nacionais e, em caso de conflito, o jusnaturalismo terá preferência sobre qualquer lei positivada.

Nesse contexto, a integração entre a lei natural e a estatal irá se traduzir na consolidação de uma instância de poder capaz de impor a negação de qualquer regra ou conduta que não esteja positivada e, a partir desse momento, verifica-se o processo de não-recepção de normas consuetudinárias ${ }^{12}$.

Conforme Lisboa (2012, p. 08), no direito constitucional é posto em relevo um dos temas clássicos da teoria do direito, ou seja, a relação entre lei como uma norma escrita e o direito em si. Diante da perspectiva jurídica do Estado de direito e do princípio da legalidade, presume-se a redução do direito à lei, implicando em uma verdadeira exclusão das demais fontes de direito.

\footnotetext{
${ }^{12}$ Vale recordar Boaventura de Sousa Santos (2003, p.06), ao afirmar que o conjunto de pressupostos que norteiam a cultura e política ocidentais estão organizados em uma entidade social chamada direito, capaz de ser definida nos seus próprios termos e de funcionar de maneira autônoma, seja das populações consideradas ferozes ou interioranas. O que definirá suas leis serão os aspectos culturais, crenças e costumes característicos do direito consuetudinário (nota do autor).
} 
A se considerar o pensamento jurídico oitocentista formado pela codificação e pela constituição, a identificação do direito à lei era ampla, o que promoveu um fenômeno de verdadeiro culto aos textos normativos.

No campo da codificação, esse culto aos textos tornou-se um dos principais traços característicos da mais destacada escola jurídica do Século XIX na França: A Escola da Exegese (LISBOA, 2012, p. 10). O texto da lei, em especial o do Código Civil Francês de 1804, é o direito que mereceu consideração e estudo por parte dos juristas, já que "os códigos não deixam nada ao arbítrio do intérprete, e esse não tem por missão fazer o direito: o direito já está feito, e plasmado no texto", o que significa que não há direito civil fora do Código Civil.

Com a quebra do consenso material que informava o Estado Liberal, o dogma da supremacia da lei e a sua caracterização como expressão da vontade geral perderam espaço. Não havia mais uma vontade geral absoluta, racional, a induzir a produção normativa, mas sim o jogo político, que é desenvolvido com base em regras formais dos textos constitucionais.

Porém, tanto o processo legislativo, enquanto procedimento de elaboração da lei, como o costume, conquanto fato produtor de normas consuetudinárias, são, sem dúvida, fontes do direito e, apesar da relevância histórica do costume, a realidade demonstra que o direito se manifesta preponderantemente por meio da lei, produto de um processo legislativo, cuja expressão é o documento escrito, registrado e promulgado segundo parâmetros estabelecidos (LISBOA, 2012, p. 32).

O predomínio da norma escrita como forma de manifestação exterior do direito ocorre em razão de vários fatores, como a maior certeza e segurança que o direito escrito proporciona quanto à extensão dos seus efeitos, sua vigência e eficácia.

Sabe-se que a norma escrita não é todo o direito, existindo situações disciplinadas por regras que não são originadas nas fontes que se manifestam mediante os textos escritos, mas que decorrem do costume, das convenções e das práticas imemoriais, cuja expressão no mundo jurídico não se dá de maneira escrita ${ }^{13}$.

A se considerar a diferença entre norma e disposição, seriam as normas não escritas aquelas que não podem ser extraídas de uma disposição contida em um texto normativo, ou seja, são normas sem disposição, mas que, de certa forma, possuem eficácia diante de seus destinatários.

\footnotetext{
${ }^{13}$ Eis uma das grandes barreiras existentes em nosso ordenamento jurídico. De que maneira pode-se considerar a força das normas consuetudinárias? (nota do autor)
} 
Essas normas não escritas, quando decorrentes do costume como expressão do poder social, ou seja, do poder decisório anônimo do povo, surgem de um sentimento difuso, que não se reduz a um ato básico, como é a promulgação. Um costume não se promulga, mas se cria, forma-se e impõe-se sem que neste processo se possa localizar um ato sancionador (LISBOA, 2012, p. 33).

A definição de Estado contemporâneo envolve numerosos problemas, derivados principalmente da dificuldade de analisar exaustivamente as múltiplas relações que se criaram entre o Estado e o complexo social e de captar, depois, os seus efeitos sobre a racionalidade interna do seu sistema político e social.

Em outro ponto, se a contribuição dos indígenas foi relevante para a construção de nossa cultura, o mesmo não se pode dizer quanto à origem do Direito nacional, pois os nativos não conseguiram impor seus "mores" e suas leis, participando mais "na humilde condição de objeto do direito real", ou seja, objetos de proteção jurídica (WOLKMER, 2003, p. 45).

Na visão de Cunha (2017, p. 253), comunidades indígenas são aquelas que, tendo uma continuidade histórica com sociedades pré-colombianas, consideram-se distintas da sociedade nacional. Índio é quem pertence a uma dessas comunidades indígenas e é por ela reconhecido. Dessa forma, pertence à sociedade indígena o direito soberano de decidir quem lhes pertence, não cabendo ao Estado interferir nesse processo, mas buscar meios de viabilizar e aperfeiçoálo diante de uma perspectiva dos direitos fundamentais dessas populações.

Como explica Candau (2008, p. 46) as “questões relativas à justiça, redistribuição, superação das desigualdades e democratização de oportunidades e as referidas ao reconhecimento de diferentes grupos culturais se faz cada vez mais estreita". Diante disso, "a problemática dos direitos humanos, muitas vezes entendidos como direitos exclusivamente individuais e fundamentalmente civis e políticos, amplia-se e, cada vez mais, afirma-se a importância dos direitos coletivos, culturais e ambientais".

Contudo, somente um fato que esteja albergado pela norma jurídica pode ser considerado um fato jurídico, ou seja, um fato gerador de direitos, deveres, pretensões e obrigações (MELLO, 1988, p. 25), o que dificulta a eficácia do direito consuetudinário em algumas questões, principalmente quando se trata de direito à propriedade.

Tendo em vista a sua influência no ambiente social e cultural, regulando a conduta humana, o direito é um fato social. A realidade do direito, deste modo, revela-se na coincidência do comportamento social com os modelos e padrões traçados pelas normas jurídicas. Como se vê, as normas do direito, embora abstratamente formuladas, tornam-se realidade no meio social, materializando-se nas condutas por elas prescritas. 
Nessa linha, constata-se que o direito pode ser manipulado e a norma ser capaz de refletir a vontade estatal, negar o clamor social ou mesmo ignorar fatos que não estejam de acordo com sua agenda política, permitindo compreender o porquê de o Estado brasileiro conseguir esvaziar as principais reivindicações dos povos indígenas.

De acordo com Luciana Roberto (2018, p. 190), a ciência do Direito surge como uma teoria hermenêutica por ter a tarefa de interpretar normas, verificar a existência da lacuna jurídica e afastar contradições normativas, sendo a teoria da decisão. Para tanto, deverá estabelecer a sistematização de normas, daí a sua função de organização, com a finalidade de decisão, ou seja, da busca de condições de possibilidade de resolução de conflitos. A ciência do Direito não se separa da técnica, do conhecimento e do domínio de meios para atingir certo objetivo, sendo instrumento de viabilização do direito das pessoas.

Importante recordar que um fenômeno social e jurídico não se esgota nas leis, sendo produto das relações humanas que não se prendem a doutrinas, dogmas, norma de decisão ou prescrições estatais, mas tem sua base nas relações entre as pessoas (FELISMINO, 2010, p. 06).

Muitos aspectos da cultura indígena estão vinculados ao Direito Consuetudinário ${ }^{14}$, sendo uma prática longínqua. Segundo Melià (2016, p. 85), o direito consuetudinário é o direito próprio, tal qual reconhecido pelo Estado paraguaio, disposto no art. 62 da Constituição Paraguaia de 1992 (PARAGUAY, 1992), que reconhece os povos indígenas como integrantes de um grupo de cultura diferente e anterior à formação e organização desse Estado nacional.

Os costumes representam fontes importantes do direito, no entanto o direito positivo vigente confere aos costumes valor secundário, colocando o direito costumeiro como algo inferior ou atrasado, como se fosse um estágio anterior à constituição do direito positivo normativo emanado pelo Estado (CURI, 2012, p. 05).

Nos dizeres de Curi (2012, p. 07), para caracterizar o direito indígena como um direito consuetudinário ou costumeiro, podemos, de modo geral, levantar dois traços específicos: 1) ele se encontra imerso no corpo social, firmemente entrelaçado com todos os outros aspectos da cultura, com o qual forma uma unidade compacta; 2) ele extrai sua força e seu conteúdo da tradição comunitária expressa nos usos e costumes.

A Constituição Federal de 1988 garantiu aos povos indígenas o resgate dos seus direitos originários como cidadãos etnicamente diferenciados mostrando a possibilidade de existência de um Estado pluriétnico, porém a letra da Constituição traz em si limitações e ineficácia a esses direitos, cuja validade e eficácia se fundamentam nos costumes.

\footnotetext{
${ }^{14}$ Direito baseado nos costumes e na ancestralidade (nota do autor).
} 
Diante dessa hipótese, vale tecer algumas considerações sobre a validade desses direitos, bem como sua força normativa e os problemas causados pela sua negação.

\section{Direito Consuetudinário: considerações acerca de sua validade, eficácia e as consequências de sua inobservância}

Considerando-se a hipótese formulada inicialmente, importa salientar que por detrás da questão demarcatória de terras indígenas e da propriedade, subsistem princípios étnicos, econômicos, culturais, jurídicos e ambientais, cuja complexidade se revela incompatível com a formação de um juízo valorativo, e a judicialização leva sempre ao binômio vencedor/perdedor, podendo ocorrer a situação em que todos perdem.

Os direitos humanos são definidos como a última fronteira de convivência e pluralismo entre os povos, ao passo que o sujeito de direitos humanos será compreendido em sua dimensão racional e emocional.

É necessário que seja estimulado um intenso debate em diversos setores da sociedade quanto ao trato deste tema tão sensível e que atinge os indígenas e suas famílias, no tocante à elaboração de leis e procedimentos capazes de normatizar essas questões, para que se evitem conflitos e violência decorrente de ações judiciais ${ }^{15}$.

Acerca do que foi visto até o momento, constata-se que o nosso sistema jurídico caminha muito lentamente no que diz respeito aos povos indígenas, fixando suas premissas em expectativas de direito e regras de eficácia limitada ${ }^{16}$, que refletem toda uma construção histórica que resultou na ineficiência do aparelho estatal e na falta de perspectivas.

Avançando na discussão proposta pela pesquisa, verificam-se diversas omissões e arranjos normativos que traduzem poucas questões envolvendo os indígenas, e as nuances da norma positivada terminou por colocar alguns pontos fundamentais de seus reclames em uma região de névoa espessa.

\footnotetext{
${ }^{15}$ Normalmente, a reintegração de posse determinada pelo Poder Judiciário tem ocasionado episódios de violência e força desproporcional contra os indígenas, considerados invasores dos territórios ocupados (nota do autor).

${ }^{16}$ Acerca das regras e sua eficácia, cabe destacar que podem possuir eficácia plena, contida ou limitada. As regras de eficácia plena dizem respeito aos direitos fundamentais dispostos no art. $5^{\circ}$ da Constituição Federal de 1988 (aplicação imediata). As regras de eficácia contida podem ser exemplificadas pela liberdade de exercer qualquer profissão, porém algumas dependem de certos requisitos, como, por exemplo, para ser advogado é necessário ser aprovado no exame da OAB. No caso das regras de eficácia limitada, essas se enquadram princípio da reserva do possível, em que o ente estatal se vale da discricionariedade para agir (conveniência e oportunidade). (nota do autor).
} 
Uma abordagem que se revela particularmente útil na investigação referente aos problemas subjacentes ao desenvolvimento do Estado contemporâneo é o da análise da difícil coexistência das formas do Estado de direito com os conteúdos do Estado social (BOBBIO, 1998, p. 401).

Recordando Kelsen (1998, p. 263), o Estado como uma realidade social estará incluído na categoria de sociedade, caracterizada por uma comunidade, e o direito estará incluído na categoria de normas; sendo um sistema de normas e uma ordem normativa nem sempre capaz de abordar todas as nuances dessa realidade.

Para que o direito consuetudinário seja eficaz, uma das alternativas é se conferir legalidade ao fato social e defendê-lo como integrante do ordenamento jurídico estatal, porém as ambiguidades e distorções na interpretação da lei, juntamente com os vazios normativos são responsáveis pela criação de um ambiente propício a abusos e violações a direitos fundamentais.

O fenômeno da incidência constitui a primordial diferença entre a norma jurídica e as regras dos demais processos de adaptação social, pois se impõe de forma obrigatória, sem sofrer qualquer influência do querer ou não-querer daqueles atingidos por seu preceito (PONTES DE MIRANDA, 1960, p. 27), sendo efeito característico da norma jurídica, seja ela cogente ou não.

Já a eficácia não é uma expressão de significação única na doutrina jurídica. Ao contrário, diversas são as significações, considerando-se a eficácia como a capacidade da norma em alcançar objetivos previamente traçados como metas, sendo a eficácia uma espécie do gênero validade, manifestação desta em sentido fático (SANTOS, 2015, p. 06).

Santos (2015, p. 07) faz uma importante indagação ao analisar a eficácia da norma diante do mundo jurídico, afirmando que eficácia é a aptidão da norma jurídica para gerar efeitos no mundo jurídico.

E o que dizer do sentido da norma sob o prisma sociológico? Faz-se mister verificar se a efetividade da norma no seio social deve necessariamente corresponder à sua eficácia jurídica, à realização do preceito abstrato contido em sua estrutura lógico-jurídica, característico de uma norma consuetudinária.

Interessante distinção entre a eficácia jurídica e social de uma norma é feita por Marcelo Neves (apud. GALINDO, 2005, p. 52), quando ensina que a primeira se refere à possibilidade jurídica de aplicação da norma, após o preenchimento das condições intrassistêmicas para produzir efeitos jurídicos específicos, enquanto a segunda se relaciona com a conformidade das condutas sociais ao preceito da norma no plano concreto, empírico. 
A capacidade conferida pela eficácia jurídica detém uma larga margem de produção de seus efeitos, podendo ser total ou parcial, plena ou limitada, ou de diversos outros modos, a depender da classificação adotada pelo jurista. Mas o fenômeno da eficácia jurídica transcende o plano lógico-formal à vista das relações do mundo real, em que se analisa a efetividade da norma aplicada.

É imperioso reconhecer que a problemática da efetividade do direito no meio social não é uma questão apenas lógica. Uma norma jurídica pode ser perfeitamente válida, juridicamente eficaz, sem, no entanto, ser efetiva, pois não se concretiza no mundo das condutas, desperdiçando a força transformadora do direito. Evidentemente, a efetividade da norma jurídica será tão presente quanto for a adesão da comunidade jurídica ao seu preceito ${ }^{17}$.

De fato, o artigo 231 da Constituição Federal de 1988 admitiu os costumes e as características dos povos indígenas, reiterados pela Convenção n ${ }^{\circ} 169$ da OIT $^{18}$ (ONU, 2015), aceita pelo Brasil, demonstrando que as normas costumeiras foram acolhidas pelo ordenamento pátrio no que concerne ao modus vivendi dos povos originários.

Conforme Kelsen (2011, p. 131), para que as normas costumeiras sejam consideradas juridicamente lícitas, no caso de não existir, em norma superior, autorização para que os órgãos competentes apliquem essas normas, "tem de se pressupor que a instituição do costume como fato produtor do direito já se operou na norma fundamental como constituição no seu sentido lógico-jurídico".

Um dos obstáculos basilares para o reconhecimento de uma Constituição como centro de valores de um ordenamento transmuda-se na concepção de que as normas postas nos textos constitucionais, referentes à esfera jurídico-privada, eram meramente programáticas, desvestidas de eficácia imediata, necessitando sempre da atividade do legislador infraconstitucional para produzirem seus efeitos.

Dessa forma, a falta de efetividade das normas constitucionais contribuiu, e ainda contribui, para gerar um enfraquecimento da credibilidade da Constituição, impedindo a formação de um sentimento patriótico-constitucional entre o povo, transformando o texto

\footnotetext{
${ }^{17}$ Hans Kelsen (2011, p. 135) afirma que que é possível admitir o costume como fato produtor de normas jurídicas, mesmo que não tenha sido institucionalizado como tal no ordenamento jurídico, bastando, para tanto, se em certo ordenamento as normas costumeiras são admitidas (nota do autor).

${ }^{18}$ A Convenção $\mathrm{n}^{\circ} 169$, sobre povos indígenas e tribais, adotada na $76^{\text {a }}$ Conferência Internacional do Trabalho em 1989, revê a Convenção $\mathrm{n}^{\circ}$ 107. Ela constitui o primeiro instrumento internacional vinculante que trata especificamente dos direitos dos povos indígenas e tribais. A Convenção aplica-se a povos em países independentes que são considerados indígenas pelo fato de seus habitantes descenderem de povos da mesma região geográfica que viviam no país na época da conquista ou no período da colonização e de conservarem suas próprias instituições sociais, econômicas, culturais e políticas (nota do autor).
} 
supremo em meras promessas sem nenhuma eficácia social. A Carta Maior passa a ser vista como um calhamaço de utopias de pouca, ou nenhuma, validade prática (FILHO, 2013, p. 25).

Já no que concerne à propriedade e suas disposições constitucionais, Moraes Filho (2020, p. 14), afirma que é um direito que não pode ser utilizado de forma individualista, mas deve satisfazer aos interesses da coletividade mediante a destinação para a sua função social. Disso deflui o fato de a propriedade que não cumpre a sua função social não ter garantia constitucional, não garantindo ao seu proprietário a plena defesa por meio das ações possessórias $^{19}$.

De acordo com Reale Junior (1992, p. 14), a propriedade exerce uma função social, realizando um fim economicamente útil, produtivo e em benefício do proprietário e de terceiros, mormente os que com o trabalho intervêm no processo de utilização de meios econômicos.

Por outro lado, o instituto da propriedade se encontra previsto no parágrafo $1^{\circ}$ do artigo 1.228 do Código Civil de 2002:

O direito de propriedade deve ser exercido em consonância com as finalidades econômicas e sociais e de modo que sejam preservados, de conformidade com o estabelecido em lei especial, a flora, as belezas naturais, o equilíbrio ecológico e o patrimônio histórico e artístico, bem como evitada a poluição do ar e das águas (BRASIL, 2002).

Desse modo, a propriedade privada também será formada e sustentada a partir de uma concepção de território, cultura, parentesco e visão de futuro, o que se evidencia no artigo 225 da Constituição Federal de 1988:

Todos têm direito ao meio-ambiente ecologicamente equilibrado, bem de uso comum do povo e essencial à sadia qualidade de vida, impondo-se ao Poder Público e à coletividade o dever de defendê-lo e preservá-lo, para as presentes e futuras gerações (BRASIL, 1988).

Barroso (2001, p. 196) ressalta que o agente econômico, público ou privado, não pode destruir o meio ambiente a pretexto de exercer seu direito constitucionalmente tutelado da livre iniciativa. Um ambiente saudável é o limite ao livre exercício da atividade econômica e, para defendê-lo e garantir a sadia qualidade de vida da população, o Estado tem o poder-dever de intervir na atuação empresarial, mediante a edição de leis e regulamentos que visem a promover o desenvolvimento sustentado.

Cavararo Rodrigues (2019, p. 77) destaca que a propriedade indígena é formada a partir das memórias desses povos, tendo como substrato a questão territorial, com o qual eles

\footnotetext{
${ }^{19}$ As ações possessórias prevista em nosso ordenamento pátrio são a ação de reintegração de posse, a ação de manutenção da posse e o interdito proibitório. São três as lesões possessórias: esbulho, turbação e ameaça, havendo uma tutela jurisdicional para cada um desses casos (nota do autor).
} 
mantêm a sua vinculação resultante de fatores como as relações de parentesco e a ancestralidade, de forma similar aos nacionais de um Estado, representativos de uma coletividade.

A proteção constitucional considera, para efeitos de ocupação e posse das terras indígenas, a data de promulgação da Constituição Federal de 1988, entendendo-se que, nessa data, caso a terra não estivesse ocupada pelos indígenas, legalmente não lhes pertenceriam ${ }^{20}$, o que é um paradoxo, pois o texto constitucional assegura aos indígenas os territórios tradicionalmente ocupados, ao menos em tese.

Entretanto, a realidade dos povos originários, à medida em que buscam somente preservar a sua cultura, seu bem viver e sua preocupação com um meio ambiente equilibrado e voltado às gerações futuras, não se alinha com os interesses econômicos, refletidos na exploração ilegal das terras originariamente ocupadas, ocasionando um ambiente de insegurança jurídica e dúvidas quanto à eficácia da norma constitucional, levando à busca de alternativas capazes de assegurar alguma margem de segurança aos territórios ocupados.

\subsection{Posse Coletiva: Possibilidades e Limites}

O grau de controle dos recursos naturais exercido pela coletividade pode ser maior ou menor, sendo controlado por um grupo familiar ou por vários ramos familiares, dependendo do grau de coesão e solidariedade existente no grupo e de como foi historicamente organizada a ocupação do território.

Benatti (1997, p. 02) destacou a necessidade de estudar o fenômeno social da posse e, partindo do contexto amazônico, apresentou uma nova noção sobre esse instituto jurídico, plenamente factível e aderente a esta pesquisa, partindo-se do pressuposto de que a legislação substantiva que trata do tema é deficiente e limitada. Além de se mostrar deficiente, essa legislação busca ser demasiadamente uniforme em sua aplicação para a vastidão territorial e para a diversidade cultural e ecológica do País e, em particular, da Amazônia.

Se por um lado, a defesa do acesso e uso comum dos recursos naturais vai estruturar a coesão social do grupo, por outro, é o conflito que possibilitará a definição dos limites da área que o grupo manterá sob o seu domínio (BENATTI, 1997, p. 04).

\footnotetext{
${ }^{20}$ Por maioria de votos, em 2014 o Supremo Tribunal Federal deu provimento ao Recurso Ordinário em Mandado de Segurança (RMS) n ${ }^{\circ} 29087$, reconhecendo não haver posse indígena em relação a uma fazenda em Mato Grosso do Sul, que integrava a terra Indígena Guyraroká (nota do autor).
} 
Num primeiro momento, é organizada toda a base de sustentação social da posse coletiva, onde o acesso à terra para o exercício das atividades agrícolas e extrativistas se dá sob a mediação de um certo grau de coesão e solidariedade, sendo construído nos momentos de litígios externos e de extrema adversidade ao grupo social. Essa reciprocidade, caracterizada pela ajuda mútua entre as comunidades, será fortalecida nos momentos de conflitos com grupos sociais que tentarem desestruturar a sua forma peculiar de apossamento.

A finalidade da terra para seringueiros, ribeirinhos e remanescentes de quilombos é inconciliável com a destinação dada pelas grandes empresas mineradoras e agropecuárias que, na maioria das vezes, estão vinculadas aos grandes projetos e interesses governamentais. Nesses momentos de conflito, a definição da faixa de terra necessária para que esses segmentos de camponeses desenvolvam suas atividades agroextrativistas torna-se essencial para estruturar os vínculos de solidariedade, forjando uma coesão social capaz de enfrentar seus adversários, como também para garantir o controle sobre sua área (BENATTI, 1997, p. 05).

A delimitação dos direitos dos indígenas sobre as áreas que são utilizadas para o cultivo e moradia familiar, enquanto outras porções de terra são reservadas para uso comum, ocorrem dentro de uma lógica espacial na qual não há a necessidade de que essas áreas (uso comum e familiar) sejam adjacentes e permanentes. Nem mesmo que suas atividades laborais e de moradia estejam confinadas em parcelas fixas. Além disso, a distribuição dos roçados, casas e a área de uso comum, segundo uma certa divisão espacial da área, ocorre baseada num consenso do grupo, e não em ações isoladas.

Nessa ótica, existem duas modalidades de apossamentos: da comunidade, que é de uso coletivo, no qual se manifesta o sistema de uso comum da terra, e o de apossamento familiar, apoiados na unidade de trabalho familiar (que pode ser entendido como "privado").

A área de uso comum significa um bem não sujeito à apropriação individual em caráter permanente. Nesses espaços combinam-se as noções de propriedade privada e de apossamento de uso comum, onde se encontra um grau de solidariedade e coesão social formada a partir de normas de caráter consensual que garantem a manutenção desses espaços.

Essas áreas possuem recursos abertos, inalienáveis e indivisíveis. $\mathrm{O}$ acesso à terra para o exercício de atividades é estritamente familiar e em parcelas da área de uso comum, sendo permitido apenas ao conjunto de moradores fazer casa, roça ou extrativismo, não podendo apropriar-se da área de uso comum em si (ibid., p. 06).

A posse comunal da terra tem um sentido público, no qual não pode haver apossamento individual e não existe a noção de uso privado ou familiar. Na relação comunal ou coletiva, as atividades produtivas são realizadas em comum, sendo que o produto é distribuído de forma 
comunal e a terra não é vista como uma mercadoria que pode ser dividida e apropriada individualmente, pois se trata de uma área imobilizada, para os fins que o grupo social lhe confere, porém, mantendo-se intactas as delimitações pré-estabelecidas em termos dos grupos sociais, parentelas e afinidades.

A Constituição Federal de 1988 instituiu um sistema de proteção social inspirado nos valores dos regimes de Estado de bem-estar social, pautado na garantia de direitos individuais, igualdade e seguridade social, entretanto esses valores se revelaram incompatíveis com o ajuste macroeconômico proposto pelas nações dominantes e a reforma liberal do Estado, que impactou as comunidades indígenas.

Na década de 1990, houve a formação de um consenso favorável ao neoliberalismo no Brasil, tendo como núcleo central da agenda liberalizante o "Estado Mínimo", que é uma antítese do Estado de bem-estar social.

$\mathrm{Na}$ ótica do neoliberalismo, o Estado de Bem-Estar representa um conflito, já que se traduz no excesso de intervenção estatal por meio de programas de assistência à população. Contudo, o núcleo do Estado mínimo não pode se desvincular de políticas voltadas ao combate da pobreza extrema, porém, diante da implantação do novo modelo de governança, a maioria da população ficou à míngua, levando ao desemprego e aumento dos bolsões de miséria.

Apesar dessas evidências, a atuação dos barões da alta finança junto ao Estado se deu por meio das políticas rentistas e do incentivo ao endividamento, além de outros fatores como corrupção, má-administração da coisa pública e falta de políticas estratégicas de longo prazo, que submeteram os governos a uma perversa agenda econômica capaz de inibir quaisquer políticas efetivamente voltadas à erradicação da pobreza e ao crescimento dos países periféricos.

Nessa lógica, os bancos e entidades financeiras, inclusive internacionais, surgem como novos atores e grandes investidores do agronegócio, possibilitando a manipulação da economia e das políticas que poderiam ser desenvolvidas em prol da população, englobando os povos originários, mas, se o Estado continuar atrelado às instituições financeiras, que lhe dão suporte, essa situação terá graves consequências.

No tocante aos efeitos dessa vinculação, pode ser citado como exemplo a busca desenfreada por novos territórios para comercialização e exploração econômica, particularmente em terras indígenas, haja vista a situação de grave endividamento do Estado e sua total falta de perspectiva e limitada visão de futuro acerca de grandes projetos de infraestrutura e melhor regulação financeira do mercado, que poderiam reverter em prol das pessoas. 
Nesse panorama, os territórios indígenas e seus recursos naturais, mais especificamente no Mato Grosso do Sul, estão vinculados a uma agenda estatal submissa aos interesses financeiros e à expansão desmedida do agronegócio, da exploração mineral e de outros recursos naturais e as terras indígenas, sendo de propriedade da União, deixam os seus usufrutuários à mercê da política estatal e ao desamparo devido à ineficácia da norma constitucional.

Se uma Constituição é definida como norma fundamental dentro de uma comunidade política e de um ordenamento jurídico, unificando e condensando em torno de si as garantias dos cidadãos e os limites do agente estatal, a realidade é que o seu alcance deve ser tal que consiga efetividade, amparando as liberdades fundamentais e reparando ilegalidades que terminam por criar estados de desvalor constitucional (MENDES, 2009, p. 574).

Direito é, também, em uma terceira acepção, a possibilidade que o beneficiário de uma norma tem de fazê-la atuar em seu favor, inclusive por meio de recurso à coação estatal. Normas jurídicas e, ipso facto, normas constitucionais tutelam bens jurídicos socialmente relevantes e interesses individuais. Um direito subjetivo constitucional confere a seu titular a faculdade de invocar a norma da Constituição para assegurar o desfrute da situação jurídica nela contemplada. Consoante doutrina clássica, é o poder de ação, fundado na norma, para a tutela de bem ou interesse próprio (BARROSO, 2018, p. 47).

$\mathrm{O}$ dever do Estado brasileiro em proteger os indígenas e respeitar seus costumes e territórios está previsto na Constituição Federal de 1988 e parte desse processo se dá por meio da demarcação de terras, contudo, não existe um modelo demarcatório claramente definido e uma política sobre o tema em vista da ineficácia da norma constitucional e do nãoreconhecimento do direito consuetudinário.

\section{Conclusão}

O Estado de Mato Grosso do Sul possui a segunda maior população indígena do país, estimada em 73.295 mil indivíduos conforme dados do IBGE, na qual se destacam os Kaiowá e Guarani, os Terena, os Kadiwéu, os Guató, os Ofaié, os Atikum e os Kiniquinau, sendo os Guarani e Kaiowá, bem como os Terena, os maiores contingentes populacionais.

Historicamente, essas sociedades sempre foram concebidas como passageiras, o que os levou a mudanças em seus territórios tradicionais levando-os a viver, atualmente, em pequenas extensões de terra consideradas como reservas indígenas pelo governo. 
A questão dos territórios indígenas no Mato Grosso do Sul é complexa, não podendo ser dissociada do longo e sistemático processo histórico de degradação cultural e social, onde a criação dos Estados Nacionais, e o seu desenvolvimento, resultaram no desprezo às práticas consuetudinárias desses povos, e sua resistência histórica, entendida como sinal de atraso, sempre representou obstáculo a projetos de infraestrutura e exploração desordenada de recursos naturais.

Dessa forma, a ocupação territorial desmedida traduziu-se, inevitavelmente, em prejuízos à tradição cultural de inúmeros povos indígenas, em paralelo à eliminação da riqueza ambiental. Em outras palavras, a apropriação dos territórios indígenas e a correspondente exploração das riquezas naturais caracteriza-se pelo crescente comprometimento da diversidade ambiental e homogeneização cultural, com graves consequências para as futuras gerações.

O progresso de uma nação se faz por meio dos grandes projetos de infraestrutura, sendo de vital importância, porém, a observância de direitos e deveres para com os cidadãos de boa-fé. Os danos causados aos povos indígenas são de difícil reparação devido à ineficiente proteção legal.

São visíveis as dificuldades de uma solução judicial acerca dos conflitos entre povos indígenas e produtores rurais, pois se atribui validade ao título de domínio conferido pelo poder público, que colide com o reconhecimento da tradicionalidade da ocupação indígena e a posse imemorial.

O bem comum se traduz na liberdade, na justiça, solidariedade e nos valores almejados pelos cidadãos, ficando acima dos interesses particulares dos indivíduos. Assim, as leis devem ter eficácia e capacidade de atender o interesse social acima de tudo, mesmo em caso da solução de conflitos duvidosos.

Sem embargo, o processo de emissão dos títulos de propriedade sem observância da ocupação desses territórios pelos indígenas resultou em expulsão e violência ao longo do tempo, refletindo a falta de uma melhor aparelhagem normativa capaz de conferir a esses povos um mínimo de segurança sobre os territórios onde habitam, garantindo seus direitos humanos primordiais ao lado do direito à vida, dignidade e costumes das civilizações.

\section{Referências}

AGUILERA URQUIZA, Antonio H. (Org.) Culturas e história dos povos indígenas em Mato Grosso do Sul. Campo Grande: Ed. UFMS, 2013. 
ALENCAR, Edna Ferreira. Estudo Estratégico. Situação Sócio-Econômica: diagnóstico dos tipos de assentamentos, demografia e atividades econômicas. Municípios de São Paulo de Olivença, Tabatinga, Amaturá e Benjamin Constant. Segundo Relatório de Campo. Santarém, PA. 2004.

BARROSO, Luís Roberto. A Ordem Econômica Constitucional e os Limites à Atuação Estatal no Controle de Preços. Revista de Direito Administrativo. n. 226. out/dez 2001. Rio de Janeiro/RJ. p. 187-212.

BARROSO, Luís Roberto. Curso de direito constitucional contemporâneo: os conceitos fundamentais e a construção do novo modelo. 7. ed. - São Paulo: Saraiva Educação, 2018.

BENATTI, José Heder. Posse coletiva da terra: um estudo jurídico sobre o apossamento de seringueiros e quilombolas. Revista CEJ, v.1, n. 3. set/dez 1997. p. 01-12.

BOBBIO, Norberto. Dicionário de política/ Norberto Bobbio, Nicola Matteucci e Gianfranco Pasquino; trad. Carmen C, Varriale et al.; coord. trad. João Ferreira; rev. geral João Ferreira e Luis Guerreiro Pinto Cacais. - Brasília: Editora Universidade de Brasília, 1 ed., 1998.

BRAND, Antonio Jacó. O confinamento e o seu impacto sobre os Pai-Kaiowá. Dissertação (Mestrado em História) - Pontifícia Universidade Católica do Rio Grande do Sul, Porto Alegre,1993.

BRASIL. Constituição Federal de 1988. Constituição de República Federativa do Brasil. Brasília, DF, 1988.

BRASIL. Lei 10.406. Código Civil Brasileiro. Brasília, DF, 10 de janeiro de 2002.

BRASIL. Mensagem de Veto $\mathbf{n}^{\mathbf{0}} \mathbf{1 6 3}$, dispõe sobre vetos à Nova Lei de Migração. Brasília, DF, 24 de maio de 2017.

CANDAU, Vera Maria. Direitos humanos, educação e interculturalidade: as tensões entre igualdade e diferença. Revista Brasileira de Educação v. 13 n. 37. p. 45-56. jan./abr. 2008.

CAVARARO RODRIGUES, Andréa Lúcia. Kaiowá-Paĩ Tavyterã: onde estamos e aonde vamos? Um estudo antropológico do Oguata na fronteira Brasil/Paraguai. Dissertação. (Mestrado em Antropologia). Universidade Federal de Mato Grosso do Sul. Campo Grande/MS. 2019.

COLMAN, Rosa Sebastiana. Guarani Retã e Mobilidade Espacial Guarani: belas caminhadas e processos de expulsão no território Guarani. Tese (Doutorado em Demografia) - Universidade Estadual de Campinas, Campinas/SP. 2015.

CUNHA, Manuela Carneiro da. Cultura com aspas e demais ensaios. São Paulo: Ubu Editora, 2017.

CURI, Melissa Volpato. O Direito Consuetudinário dos Povos Indígenas e o Pluralismo Jurídico. Revista Espaço Ameríndio, v. 6, n. 2, p. 230-247, UFRGS, Porto Alegre/RS, jul./dez. 2012. 
EREMITES DE OLIVEIRA, Jorge; PEREIRA, Levi. Ñande Ru Marangatu. Laudo antropológico e histórico sobre uma terra kaiowá na fronteira do Brasil com o Paraguai, município de Antônio João, Mato Grosso do Sul. Dourados: Editora UFGD, 2009.

FELISMINO, Lia Cordeiro. Pluralismo jurídico: um diálogo entre os pensamentos emancipatórios de Boaventura de Sousa Santos e Antônio Carlos Wolkmer. Anais XIX Encontro Nacional do CONPEDI realizado em Fortaleza - CE nos dias 09, 10, 11 e 12 de Junho de 2010.

FILHO, Edilson Santana Gonçalves. Tutela Cautelar como Garantia Fundamental. Revista Jurídica Faculdade 7, v. X, n. 1, p. 21-31, Fortaleza, CE. Abr. 2013.

GABAGLIA, Fernando Raja. Fronteiras do Brasil. Disponível em $<$ http:// archive.org/details/asfronteirasdobr00gaba>. Acesso em 09 set. 2014.

GALINDO, Bruno. Direitos fundamentais. $1^{\mathrm{a}}$ ed. Curitiba: Juruá, 2005.

HECK, José. Origens e aporias do jusnaturalismo moderno. Ethic@ Revista Internacional de Filosofia da Moral. v.7, n.2, p. 215-232. Florianópolis, SC, dez. 2008.

KELSEN, Hans. Teoria Geral do Direito e do Estado. 3 ed. São Paulo: Martins Fontes, 1998.

KELSEN, Hans. Teoria Pura do Direito. 7 ed. rev. São Paulo: Editora RT, 2011.

LISBOA, Carolina Cardoso Guimarães. Normas Constitucionais Não Escritas: Costumes e Convenções na Constituições. Tese de Doutorado. Programa de Pós-Graduação em Direito. Universidade de São Paulo. São Paulo, SP, 2012. 243p.

LUCIANA ROBERTO, Mendes Pereira. Resenha. Revista Jurídica da UniFil. Ano IV. n. 4, 2018. p. 187-191.

MELIÀ, Bartomeu. Camino guaraní: de lejos veninos, hacia más lejos caminamos. Centro de Estudios Paraguayos"; Antonio Guasch". Asunción. 2016.

MELLO, Marcos Bernardes de. Teoria do Fato Jurídico. 3 ed. São Paulo: Saraiva, 1988.

MORAES FILHO, Odilon Carpes. A Função Social da Posse e da Propriedade nos Direitos Reais. Disponível em http://www.amprs.org.br/arquivos/comunicao_noticia/odilonm2.pdf. Acesso em 20/02/2020.

MORIN, Edgar. Introdução ao Pensamento Complexo. 3. ed. Porto Alegre: Sulina, 2011.

MENDES, Gilmar Ferreira. Curso de Direito Constitucional. 4. Ed. Rev. e atualizada. São Paulo: Saraiva, 2009.

ONU. Convenção $\mathbf{n}^{0} 169$ sobre povos indígenas e tribais e Resolução referente à ação da OIT. Disponível em: < http://www.oitbrasil.org.br/node/292>. Acesso em 23/04/2015.

PARAGUAY: Constitución de la República de 1992. 
PONTES DE MIRANDA. Francisco Cavalcante. Comentários à Constituição de 1946. I, $3^{\mathrm{a}}$ ed. Rio de Janeiro: Borsoi, 1960.

REALE JÚNIOR, Miguel. Casos de direito constitucional. São Paulo: Ed. Revista dos Tribunais, 1992.

SANTOS, Boaventura de Sousa. Poderá o direito ser emancipado? - Revista Crítica de Ciências Sociais. Universidade de Coimbra, n. 65, p. 3-76, mai. 2003.

SANTOS, Kleidson Nascimento dos. Eficácia Jurídica e Eficácia Social: Apontamentos sobre a Norma Jurídica e a Efetividade do Direito. Revista do Curso de Direito - Faculdade de Administração e Negócios de Sergipe - FANESE - Sergipe/SE - Vol. V - No 1 - outubro de 2015.

SILVA, José Afonso da. Terras Tradicionalmente ocupadas pelos índios. In: Os Direitos Indígenas e a Constituição. $8^{a}$ edição. Curso de Direito Constitucional Positivo. São Paulo: Malheiros Editores, 1992. p. 45-50.

STF. Recurso em Mandado de Segurança n 29.087, Relator(a): Min. Ricardo Lewandowski, julgado em 16/09/2014, publicado em DJ 14/10/2014. Disponível em <www.stf.jus.br>. Acesso em 15 mai. 2020.

WIEACKER, Franz. História do Direito Privado Moderno. 2 ed. Fundação Calouste Goubenkian. Lisboa, 1967.

WOLKMER, Antonio Carlos. História do direito no Brasil. Rio de Janeiro: Forense, 2003.

Data de recebimento: 03.03.2021

Data de aprovação: 16.07.2021 